\title{
A!
}

This is an electronic reprint of the original article.

This reprint may differ from the original in pagination and typographic detail.

Hurme, S.; Marquis, G.

\section{Fatigue experiments and finite element analysis of bolted/bonded double lap joints}

Published in:

Welding in the World

DOI:

$10.1007 / s 40194-014-0157-4$

Published: 01/01/2014

Document Version

Peer reviewed version

Please cite the original version:

Hurme, S., \& Marquis, G. (2014). Fatigue experiments and finite element analysis of bolted/bonded double lap joints. Welding in the World, 58(6). https://doi.org/10.1007/s40194-014-0157-4

This material is protected by copyright and other intellectual property rights, and duplication or sale of all or part of any of the repository collections is not permitted, except that material may be duplicated by you for your research use or educational purposes in electronic or print form. You must obtain permission for any other use. Electronic or print copies may not be offered, whether for sale or otherwise to anyone who is not an authorised user. 


\title{
FATIGUE EXPERIMENTS AND FINITE ELEMENT ANALYSIS OF BOLTED/BONDED DOUBLE LAP JOINTS
}

Authors: S. Hurme*, G. Marquis

S. Hurme $(*)$, G. Marquis

Department of Applied Mechanics, Aalto University,

P.O. Box 14300, 00076 Aalto, Finland

e-mail: susanna.hurme@aalto.fi

\begin{abstract}
:
High-strength steel hybrid joints that combine adhesive and bolts have been studied both experimentally and numerically. The fatigue strength of the double lap joint has been experimentally measured under completely reversed cyclic loading. Finite element analysis was used to estimate the stress state at the contact interface of the lap joint. The fatigue strength of bonded and clamped interfaces which have previously been characterized using napkin ring specimens has been combined with the finite element results. The region of the double lap joint which showed fretting damage corresponded well with the region estimated to have significant damage based on the assessment. The resulting fatigue strength assessment was conservative with respect to the experimental results.
\end{abstract}

IIW Keywords:

Adhesive bonding; Bolts; Fatigue strength; Fatigue tests; Finite element analysis 


\section{Nomenclature}

\begin{tabular}{|c|c|}
\hline$d$ & $\begin{array}{l}\text { Loading level interval between subsequent fatigue tests in the small sample staircase } \\
\text { series }\end{array}$ \\
\hline$D$ & Damage variable of the cohesive interface model \\
\hline E & Young's modulus \\
\hline$F$ & Longitudinal load applied to the double lap joint specimen \\
\hline$F_{a}$ & Load amplitude applied during the double lap joint experiment \\
\hline$F_{a, 0}$ & First load amplitude level of the staircase sequence \\
\hline$F_{a, f}$ & Load amplitude corresponding to the estimated fatigue strength \\
\hline$G_{c}$ & Fracture energy \\
\hline$k$ & Parameter based on the staircase sequence \\
\hline$K_{n n}, K_{s s}, K_{t t}$ & Cohesive stiffness component in the normal and in the two shear directions, respectively \\
\hline$N_{f}$ & Number of cycles to failure \\
\hline$P$ & Longitudinal load applied to the double lap joint finite element model as surface pressure \\
\hline$P_{\max }$ & Maximum load during the double lap joint simulation \\
\hline$P_{\min }$ & Minimum load during the double lap joint simulation, maximum compressive load \\
\hline $\begin{array}{l}q \\
t_{n}, t_{s}, t_{+}\end{array}$ & $\begin{array}{l}\text { Static normal stress on the interface of the modified napkin ring specimen } \\
\text { Cohesive traction in the normal and in the two shear directions, respectively }\end{array}$ \\
\hline $\bar{t}_{n}, \bar{t}_{s}, \bar{t}_{t}$ & $\begin{array}{l}\text { Elastic traction without damage in the normal and in the two shear directions, } \\
\text { respectively }\end{array}$ \\
\hline$t_{n}^{0}, t_{s}^{0}, t_{t}^{0}$ & Critical cohesive traction in the normal and in the two shear directions, respectively \\
\hline$\alpha$ & Coefficient of the exponential damage evolution model \\
\hline$\Delta$ & Interface relative displacement during a modified napkin ring experiment \\
\hline$\Delta_{\text {gap }}$ & Displacement measured by the clip-on gage during the double lap joint test \\
\hline$\Delta_{\text {tot }}$ & Total displacement measured by the built-in sensor during the double lap joint test \\
\hline$\delta_{n}, \delta_{s}, \delta_{t}$ & $\begin{array}{l}\text { Cohesive relative displacement in the normal and in the two shear directions, } \\
\text { respectively }\end{array}$ \\
\hline$\delta_{m}$ & Effective separation \\
\hline$\delta_{m}^{0}$ & Effective separation at onset of damage \\
\hline$\delta_{m}^{f}$ & Effective separation at full cohesive fracture \\
\hline$\delta_{m}^{\max }$ & Maximum effective separation attained during the loading history \\
\hline$\mu$ & Coefficient of friction \\
\hline$v$ & Poisson's ratio \\
\hline$\sigma_{2}$ & Calculated contact pressure on the interface \\
\hline$\tau_{1}$ & Calculated interface shear stress along the global 1-direction \\
\hline$\tau_{\|}$ & Measured shear stress during a modified napkin ring experiment \\
\hline$\tau_{f}$ & $\begin{array}{l}\text { Shear stress amplitude corresponding to the estimated fatigue strength of the bonded and } \\
\text { clamped interface }\end{array}$ \\
\hline \multicolumn{2}{|l|}{ Abbreviations } \\
\hline CZM & Cohesive zone modelling \\
\hline DLJ & Double lap joint \\
\hline FEM & Finite element method \\
\hline HSS & High-strength steel \\
\hline
\end{tabular}




\section{Introduction}

High-strength steels (HSS) are increasingly used to deliver light weight and improved strength in structures. However, the durability of an HSS structure depends highly on the welded joints, the fatigue strength of which does not increase proportionally with the steel strength. Hybrid joints, where the good properties of adhesives and mechanical fasteners or spot welds are combined, provide potential joining alternatives for improved fatigue resistance in high-strength steel structures. The current study focuses on hybrid joints that combine adhesives and bolts. With the use of these joints, the load is carried by both adhesion and friction. The primary loading mode of the joint is cyclic shear stress combined with static normal stress.

An in-depth understanding of the behaviour of the clamped and bonded interface during quasi-static as well as fatigue loading is needed, in order to fully exploit the potential of the hybrid joint, where two load-carrying mechanisms are combined to yield a joint stronger than either mechanism alone. In addition, a failure assessment method needs to be developed along with an appropriate test method. A test method using a modified napkin ring specimen which combines shear and normal stresses was introduced [1-4]. The method allows for the characterization of interface properties with very welldefined boundary conditions. Previously, static behaviour was successfully characterized by using the cohesive zone modelling (CZM) approach $[2,4]$. High-cycle fatigue behaviour was studied via a series of constant amplitude fatigue tests [1]. As a result, the fatigue strength at $2 \times 10^{6}$ cycles was measured under several clamping stress conditions by using the small sample staircase method [5-7].

The response of bonded/bolted hybrid joints is inherently a combination of the behaviour of bolted joints and adhesive joints. The fatigue failure mechanisms of the bonded and clamped interface were identified in [1]. It was observed that for areas under low clamping stress, the failure was governed by shear decohesion, which is failure related to the adhesive. Under high clamping stress conditions, however, the failure was mainly due to fretting fatigue, which is a common problem encountered in the use of bolted frictional joints.

Fretting damage occurs at interfaces which are in contact and which are subject to clamping and cyclic tangential micro-slipping. High local stresses at the partial-slip area at the edge of contact can cause damage and crack initiation at the surface. Initially, the crack propagates through the volume affected by contact stresses, and later the propagation is driven by stresses in the bulk material. The crack propagation is governed by multiaxial stresses, variable R-ratio and non-proportional stresses because of the non-linear nature of the frictional stress. An extensive number of studies has been published about the fretting fatigue phenomenon, including experimental, analytical and numerical studies, some reviews of which are found for example in [8-10]. The fatigue in bolted joints has been studied by [11-13] and it has been shown that the failure mechanism is determined by the clamping load. With low clamping the crack initiates at the edge of the bolt hole, while intermediate clamping results in fretting wear and with high clamping, the failure type is fretting fatigue with crack initiation at the edge of the contact area. Fatigue strength improves with increased clamping until fretting fatigue starts to dominate. Thereafter, no improvement in fatigue strength is obtained by an increase in clamping.

Numerous published research papers have also focused on the analysis of adhesive joints. The stress analysis of the simplest adhesive shear joint, the thin-lap shear specimen, has been studied extensively since the introduction of the shear lag model by Volkersen [14]. A good state-of-the-art review is provided by Kwakernaak et al. [15]. Analytical stress analysis studies of more complex geometries such as the double lap joint have been published as well [16-18]. In addition to analytical studies, many researchers have applied the finite element method (FEM) for calculating the stresses in the adhesive 
joint [19]. The fundamental issue regarding finite element modelling of adhesive joints is the scale problem; the thickness of adherends is usually in the millimetre range, while the adhesive layer thickness measures only a few micrometres. The failure in adhesive joints is often assessed by the fracture mechanics approach. Instead of using the stress intensity factor, the strain energy release rate approach introduced by Griffith [20] is usually applied in fracture mechanics studies of adhesive joints. Recently, the cohesive zone modelling (CZM) technique has become widely used in failure modelling of adhesive joints $[21,22]$. The CZM approach has the advantage of being able to account for both the initiation and the propagation of debonding, thus combining the advantages of strengthbased and fracture mechanics-based approaches to failure analysis. Some researchers have introduced a fatigue damage parameter into the CZM process to model interface degradation under fatigue loading [23-25].

The cohesive zone modelling technique is adopted here for the assessment of the bonded and bolted high-strength steel joint. The main focus of the hybrid joint assessment is the interaction of friction and the cohesive tractions in the bonded and clamped interface. The commercial finite element software Abaqus provides the surface-based cohesive contact property definition feature, which can be utilized for the modelling of the cohesive and frictional interface. The main advantage of the approach is that the interaction of friction and cohesion is automatically modelled so that frictional traction is increased in proportion to the damage at the contact point. Thus, whereas the contact tractions are initially governed by cohesion, once damage initiates, friction starts to contribute to the tractions.

This paper presents a methodology to determine the cohesive model parameters from modified napkin ring experiments. With the parameters calibrated, the cohesive and frictional contact properties are used in a model of the double lap joint (DL). Through quasi-static simulations on the $\mathrm{DL}$, the locations and magnitude of the maximum shear stresses in the bonded and clamped interface can be determined. The stresses at the interface are compared to normal stress/shear stress conditions that have been observed to correspond to the interface fatigue strength at $2 \times 10^{6}$ cycles [1].

The fatigue failure of the bonded/bolted interface involves progressive damage of the adhesive and simultaneous fretting damage and, thus, is a fairly complicated phenomenon. It should be pointed out that a unified failure model which includes both failure mechanisms does not exist, so the design of the hybrid joint requires careful analysis and consideration by the designer. As an attempt to assess the fatigue behaviour of such a bonded/bolted HSS joint, the analysis of this paper aims to estimate the fatigue strength of the joint at $2 \times 10^{6}$ cycles. The results of the simulations are compared to fatigue experiments of the bonded/bolted DL. The fatigue strength is obtained experimentally by using the small sample staircase method [5-7]. In addition, fatigue tests with higher load amplitudes are reported and the failure mechanisms of the joint are discussed.

\section{Double lap joint experiments}

The experiments on the double lap joint consist of a small sample staircase series for obtaining an estimate of the fatigue strength [5-7], a few fatigue tests at short lives and quasi-static tests for both the bonded/bolted joint and plain bolted joint with the non-bonded condition. In addition, three single tests were performed with slightly modified test set-ups in order to clarify the failure mechanism.

\subsection{Specimen}

The specimen bore the double lap geometry as shown in Fig. 1. All parts of the specimen were cut from an 8-mm thick, high-strength steel plate (RUUKKI Optim 960 QC, nominal yield strength 960 $\mathrm{MPa}$ ). The assembly consisted of two main plates, and two top plates attached with one high-strength 
M12 bolt and one M20 bolt and bonded with the two-component epoxy adhesive DP760 by 3M. The oversized M20 bolt was used to ensure a non-slip connection on one side of the specimen. The diameter of the hole for the M12 bolt measured $14.5 \mathrm{~mm}$, which resulted in a clearance radius of 1.25 $\mathrm{mm}$. The clearance ensured that the slipping of the hybrid interface did not lead to the load being carried by bolt shear.
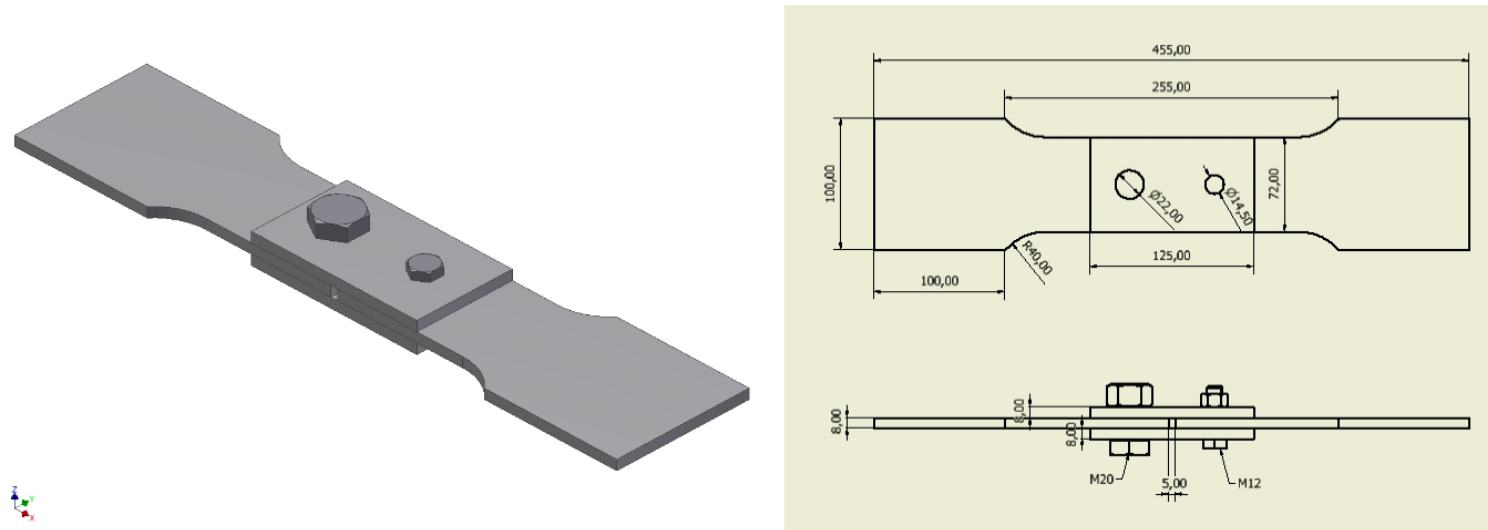

Figure 1. Geometry and dimensions in [mm] of the double lap joint.

The contact surfaces of the plates were grit-blasted with aluminium oxide to average surface roughness of $R_{a}=2.7 \mu \mathrm{m}$. Prior to bonding, the plates were cleaned in an ultrasonic bath and then wiped with ethanol to ensure optimal bonding. The adhesive was applied to both top plates which were then immediately bolted to the main plates. After assembly, the adhesive was cured in an oven at $65^{\circ} \mathrm{C}$ for 2 hours. The specimen was allowed to cool down to room temperature before testing.

The M12 bolt was tightened to $130 \mathrm{Nm}$, which corresponds to $43+-4.5 \mathrm{kN}$ axial load. The axial load was determined by measurements using a shim load cell. Eight bolts were selected for the calibration. The bolts were tightened using a torque wrench, and the axial load corresponding to each tightening torque was measured. The ratio of the applied tightening torque to the measured axial load is shown in Fig. 2, with a solid line at the mean and dashed lines at two standard deviations from the mean. The scatter in the resulting axial load was due to the method used for tightening the bolts. The accuracy of the axial load is affected by the torque wrench, geometric defects on the thread and bearing surfaces, and lubrication of the bearing surfaces. However, the accuracy of the bolt tightening using the torque wrench was considered to be good enough. Another possibility would have been to instrument each bolt with a strain gage, but this was not cost effective as the bolts went through a permanent distortion at specimen failure, and could not be re-used. The large M20 bolt was tightened to $200 \mathrm{Nm}$. 


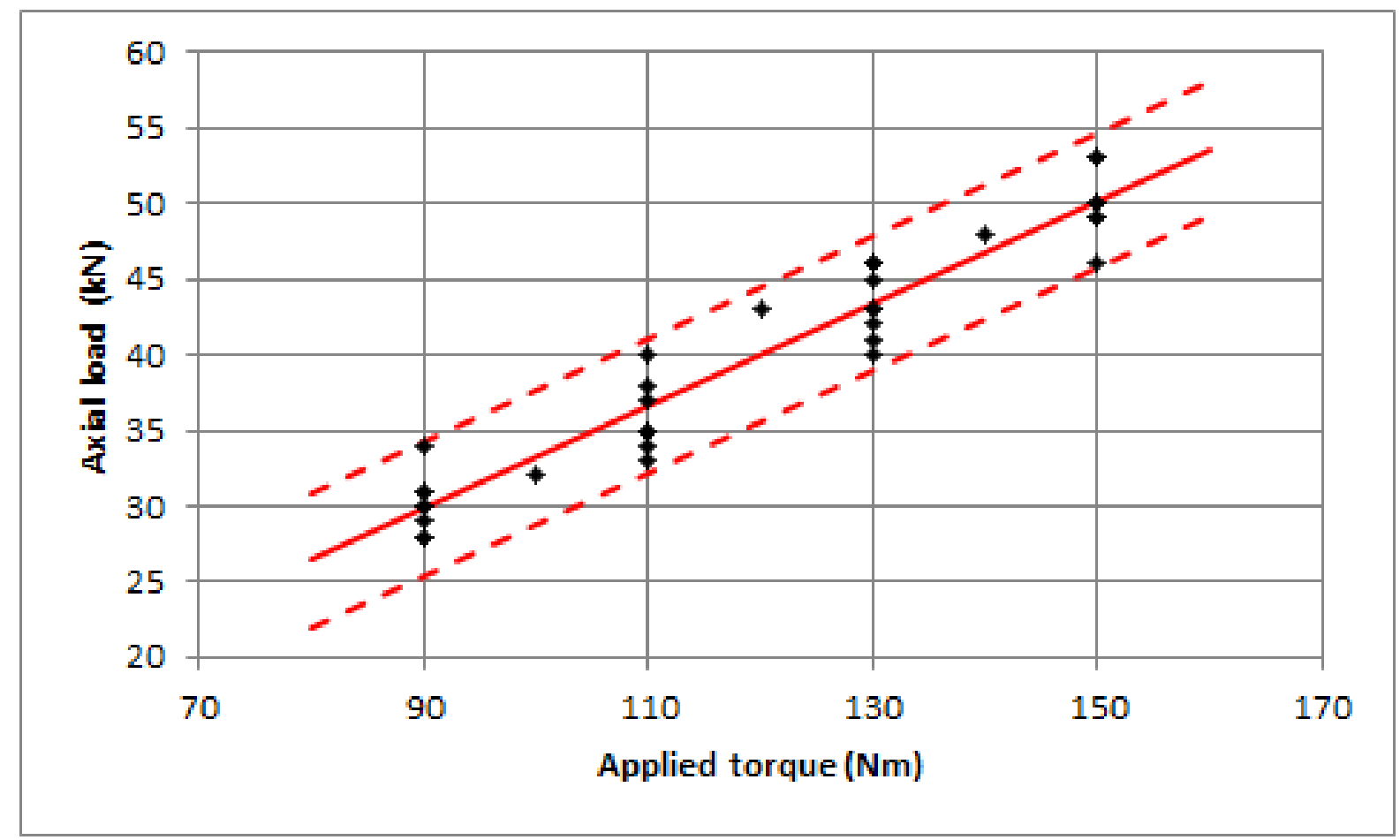

Figure 2. The ratio of the applied torque to the measured axial load for eight M12 bolts. The mean line and the lines at two standard deviations are shown for the data set.

\subsection{Laboratory test procedure}

The fatigue tests were conducted using an MTS Landmark 370.25 servohydraulic test system. The loading was applied in force control at load ratio $R=-1$ and at the frequency of $15 \mathrm{~Hz}$. The constant amplitude fatigue test continued until $2 \times 10^{6}$ cycles had been attained or until a displacement of $1 \mathrm{~mm}$ was measured by the built-in displacement sensor. Due to high loads and elastic strains in the main body of the specimen, the displacement amplitudes measured at the ends of the specimen during testing were in the range of $0.5 \mathrm{~mm}$ for undamaged joints. However, the displacement due to interface slipping was much smaller. In order to capture the slipping, the width of the 5-mm gap between the main plates was monitored by an MTS Model 632.02 clip-on gage from one side of the specimen. A photograph of the test setup is shown in Figure 3. 


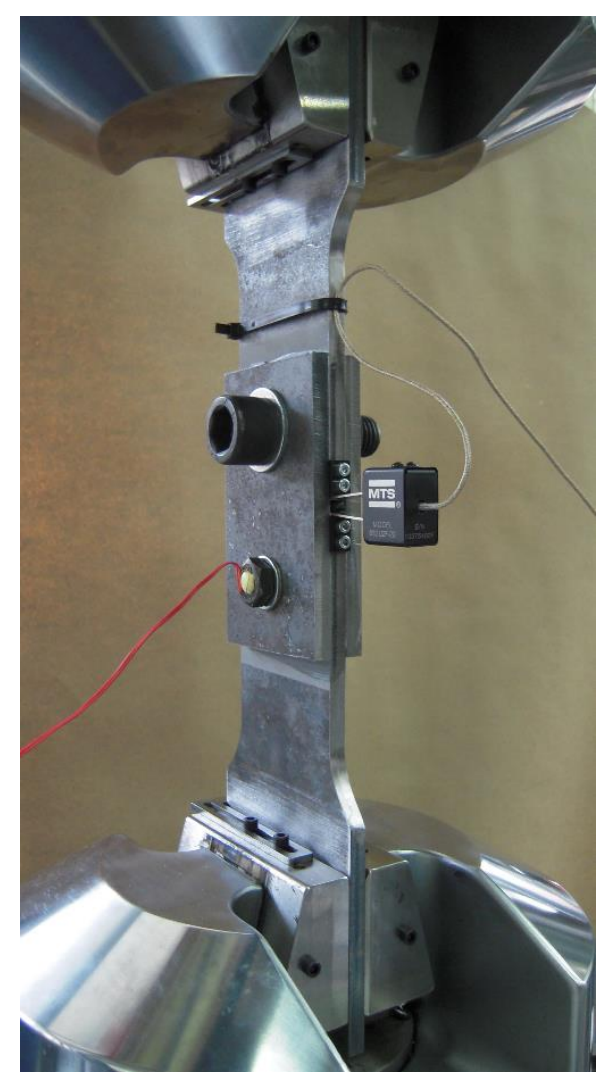

Figure 3. Photograph of the experimental setup for constant amplitude fatigue tests on the double lap joint.

Some of the fatigue tests were implemented according to the small sample staircase scheme [5-7]. In the staircase method, the loading amplitude is either increased or decreased by a definite interval, based on the response of the previous test. For example, if the previous test was conducted at a loading amplitude of $F_{\mathrm{a}}=80 \mathrm{kN}$, and it was a run-out, the next test would be carried out at the amplitude of $F_{a}=85 \mathrm{kN}$. All but the last of the beginning specimens with like response are ignored when constructing the staircase sequence. For example, if the first test resulting in a failure was carried out at a loading amplitude of $F_{\mathrm{a}}=85 \mathrm{kN}$, and before that tests had been performed at loading amplitudes of $F_{\mathrm{a}}=70 \mathrm{kN}, F_{\mathrm{a}}=75 \mathrm{kN}$ and $F_{\mathrm{a}}=80 \mathrm{kN}$ with all of them resulting in a run-out, the test to start the staircase sequence would be the one with the loading amplitude of $F_{\mathrm{a}}=80 \mathrm{kN}$, and the earlier tests would be ignored. The length of the staircase sequence should be 2-6 tests. According to the staircase sequence methodology, the estimate for the mean of the fatigue strength, $F_{a, f}$, is obtained from Equation (1)

$$
F_{a, f}=F_{a, 0}+k d
$$

where $F_{a, 0}$ is the first load amplitude level in the sequence, $k$ is a parameter dependent on the sequence and on the underlying distribution and can be found in [7], and $d$ is the loading interval.

Quasi-static fracture tests were performed on the bonded/bolted and plain bolted specimens. The quasi-static loading was applied in displacement control at the rate of $0.01 \mathrm{~mm} / \mathrm{s}$. In addition, some fatigue tests with shorter lives (higher load) were performed.

\section{Finite element model of the DLJ}


The adherends, bolt and washer were modelled as linear-elastic with the mechanical properties corresponding to steel ( $E=210 \mathrm{GPa}, \mathrm{v}=0.3$ ). The 8-node linear brick elements C3D8R with reduced integration were used for all parts [26]. Only one quarter of the bonded slip area of the lap joint was modelled in order to reduce the calculation time. The geometry of the model is shown in Fig. 4. All translations are restrained at the back end of the top plate (area B in Fig. 4) and the cutting planes have the symmetry boundary condition.

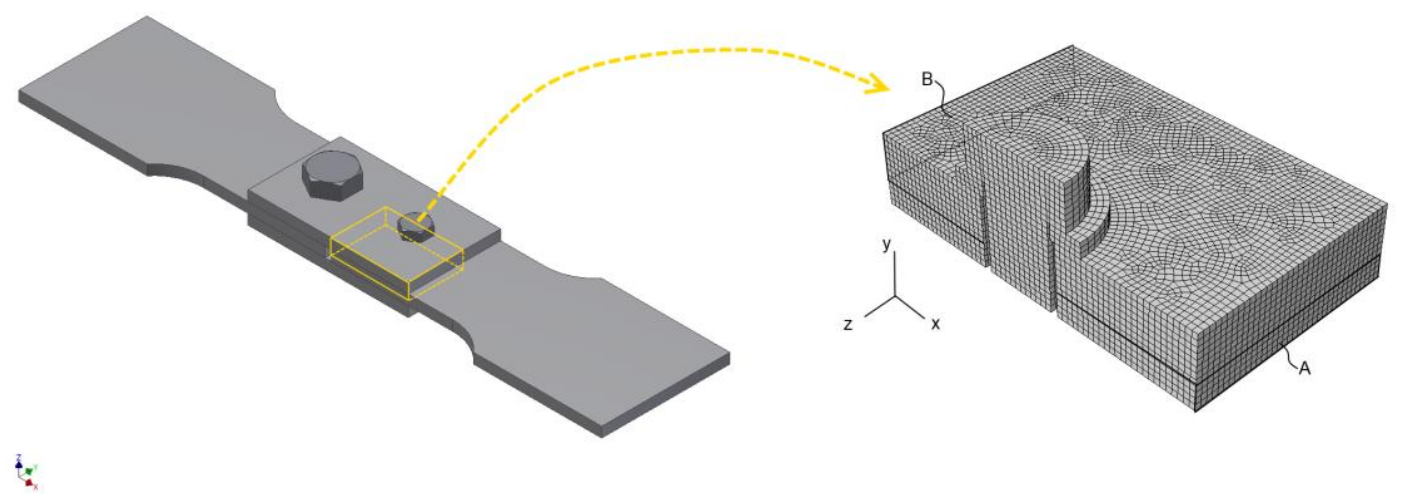

Figure 4. Finite element model of one quarter of the bonded slip area of the double lap joint.

The contact interaction at the interface between the two plates was defined as having combined cohesive and frictional behaviour. Other contacts in the model (between bolt, washer and adherend) were defined using the penalty friction model and the hard normal contact which allows for no penetration. The coefficient of friction outside of the bonded contact area was chosen to be $\mu=0.2$, a typical coefficient for untreated steel contact.

The analysis was performed in two steps. In the first step, the bolt load of $21500 \mathrm{~N}$ was applied at the bolt cross-sectional area. In the next step, the uniform pressure load of $P_{\max }=139 \mathrm{MPa}$ (corresponding to approximately $F=80 \mathrm{kN}$ loading in the experiments) was applied to face A in Fig. 4. following a smooth-step amplitude while the bolt load remained constant. The unloading and loading to the maximum longitudinal compression of $P_{\min }=-139 \mathrm{MPa}$ was subsequently applied, following the smooth-step amplitude. The tractions at the cohesive interface were reported in the CSTRESS surface output variables.

\subsection{The cohesive and frictional contact model}

The bonded interface was modelled with a traction-separation cohesive law [26] combined with Coulomb friction. Initially linear elastic behaviour is assumed. The tractions are related to the separations through a stiffness matrix

$\mathbf{t}=\left\{\begin{array}{l}t_{n} \\ t_{s} \\ t_{t}\end{array}\right\}=\left[\begin{array}{lll}K_{n n} & K_{n s} & K_{n t} \\ K_{n s} & K_{s s} & K_{s t} \\ K_{n t} & K_{s t} & K_{t t}\end{array}\right]\left\{\begin{array}{l}\delta_{n} \\ \delta_{s} \\ \delta_{t}\end{array}\right\}=\mathbf{K} \delta$

The components of the traction vector $t_{n}, t_{s}, t_{t}$, correspond to the normal and the two shear tractions, respectively. The corresponding separations are $\delta_{n}, \delta_{s}$ and $\delta_{t}$. The stiffness matrix is defined as uncoupled by setting all of the off-diagonal stiffness parameters to zero. 
The failure criterion is defined by maximum nominal stresses. Damage is assumed to initiate at a contact point when the ratio of traction and critical traction reaches the value of one, as shown in Equation (3).

$\max \left\{\frac{\left\langle t_{n}\right\rangle}{t_{n}^{0}}, \frac{t_{s}}{t_{s}^{0}}, \frac{t_{t}}{t_{t}^{0}}\right\}=1$,

where $t_{n}^{0}, t_{s}^{0}, t_{t}^{0}$ are the critical tractions in the normal and in the two shear directions, respectively. The Macaulay brackets \langle\rangle indicate that purely compressive traction does not initiate damage. Further loading causes the traction to be degraded according to the damage evolution equation, which can be linear, exponential or user-defined. After damage initiation, the tractions are defined as

$t_{n}=\left\{\begin{array}{l}(1-D) \bar{t}_{n}, t_{n} \geq 0 \\ \bar{t}_{n}, \quad \text { otherwise }\end{array}\right.$

$t_{s}=(1-D) \bar{t}_{s}$

$t_{t}=(1-D) \bar{t}_{t}$

where $D$ is a scalar damage variable and $\bar{t}_{n}, \bar{t}_{s}, \bar{t}_{t}$ are the traction components according to the elastic traction-displacement behaviour without damage. The conditions of the normal traction component indicate that no damage evolution occurs if the normal stress is compressive.

In order to define damage under multiaxial loading conditions, the effective separation is defined:

$$
\delta_{m}=\sqrt{\left\langle\delta_{n}\right\rangle^{2}+\delta_{s}^{2}+\delta_{t}^{2}}
$$

In this work, the damage evolution is defined as exponential degradation of the traction stress as shown in Figure 5. The model is initially linear-elastic until one of the traction components reaches its critical value. The separation corresponding to the critical traction is denoted as $\delta_{m}{ }^{0}$. After damage initiation, the traction degrades exponentially until the attainment of relative displacement at full separation, $\delta_{m}{ }^{f}$. For relative displacement beyond $\delta_{m}{ }^{f}$, there are zero cohesive tractions. The area under the traction-separation law is defined as the fracture energy, $G_{c}$. 


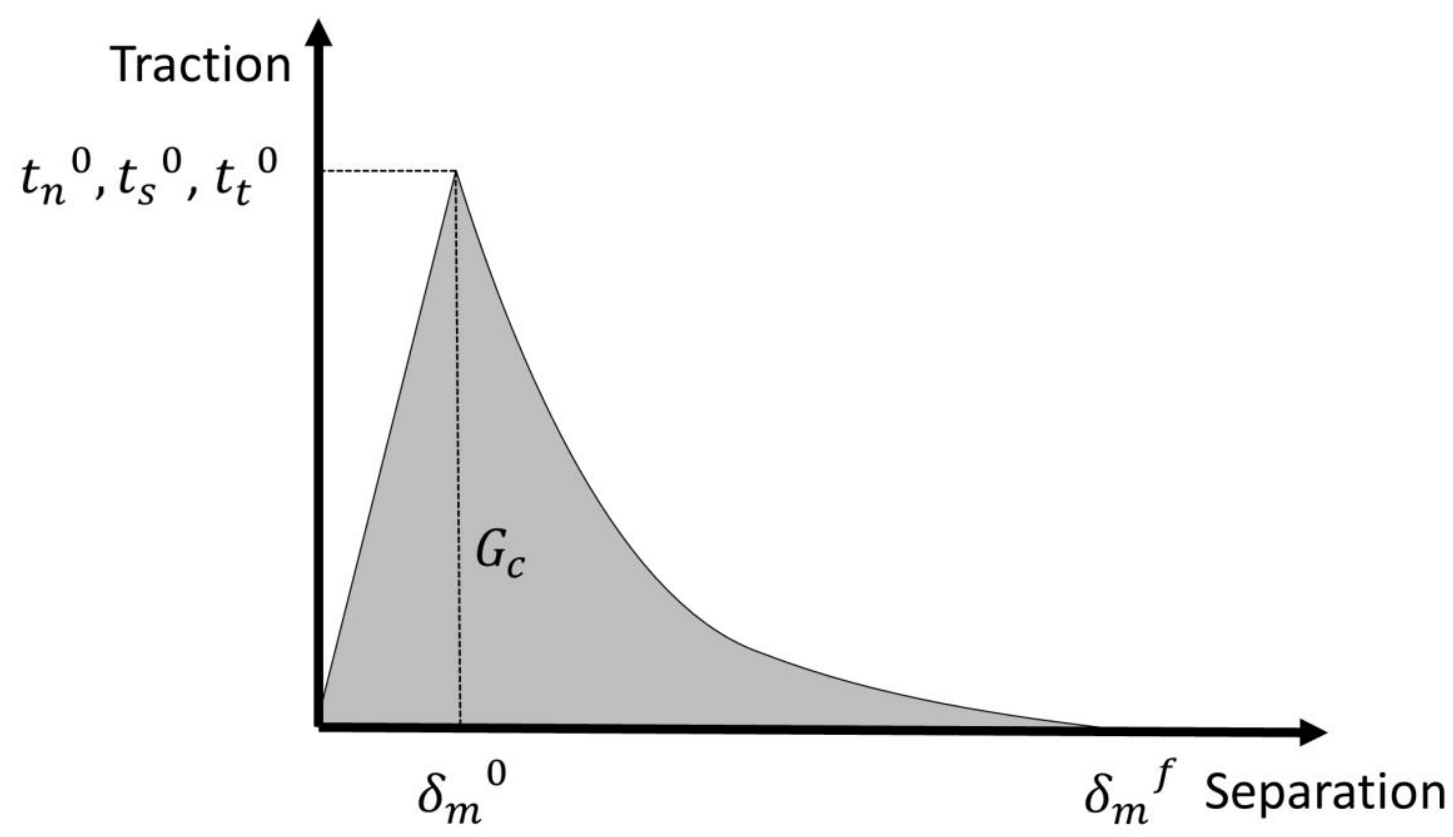

Figure 5. Traction-separation cohesive law with the exponential damage evolution.

The damage variable $D$ for the exponential damage evolution is defined as

$$
D=1-\left\{\frac{\delta_{m}^{0}}{\delta_{m}^{\max }}\right\}\left\{1-\frac{1-\exp \left(-\alpha\left(\frac{\delta_{m}^{\max }-\delta_{m}^{0}}{\delta_{m}^{f}-\delta_{m}^{0}}\right)\right)}{1-\exp (-\alpha)}\right\}
$$

where $\alpha$ is a non-dimensional parameter and $\delta_{m}{ }^{\text {max }}$ is the maximum relative displacement at the contact point.

The surface-based cohesive behaviour allows for the incorporation of frictional effects into the interface response. If both tangential frictional behaviour and surface-based cohesive behaviour are defined in the interaction property, the frictional model will be activated once damage has initiated. The frictional traction is increased in proportion to the damage and the total traction components at a contact point become

$t_{s}=\left\{\begin{array}{l}(1-D) \bar{t}_{n}, \bar{t}_{n} \geq 0 \\ \bar{t}_{n}, \text { otherwise }\end{array}\right.$

$t_{s}=\left\{\begin{array}{lr}(1-D) \bar{t}_{s}, & \bar{t}_{n} \geq 0 \\ (1-D) \bar{t}_{s}-D \mu \bar{t}_{n}, & \text { otherwise }\end{array}\right.$

$t_{t}=\left\{\begin{array}{l}(1-D) \bar{t}_{t}, \quad \bar{t}_{n} \geq 0 \\ (1-D) \bar{t}_{t}-D \mu \bar{t}_{n}, \text { otherwise }\end{array}\right.$

The hybrid cohesive and frictional behaviour can also be modelled with cohesive elements, as was conducted in [2]. However, the incorporation of friction requires that the stiffness in the positive 
normal direction be defined as $K_{n n}=0$. A small amount of positive normal stress is unavoidable in the double lap joint, thus the assumption of zero normal stiffness will lead to inaccuracy. This is the main reason why the cohesive behaviour was introduced as a contact property instead of using cohesive elements.

\subsubsection{Modified napkin ring tests}

The properties of the combined cohesive and frictional interface were derived from quasi-static tests on the modified napkin ring specimens. The experimental set-up will only briefly be summarized here and a more detailed description can be found in [1-4]. The modified napkin ring specimen (Figure 6) was developed in order to study the fatigue and quasi-static fracture of the bonded and clamped interface under mode II loading. Two specimen halves were glued together with the two-component epoxy adhesive DP760 by 3M. A constant axial pressure was applied by a threaded rod that was inserted through the centre hole of the specimen. The axial compression was maintained throughout curing and subsequent testing. Adhesive was applied only to the annular contact area, to ensure only minimal variation in shear stress due to distance from the centre. With very well-defined boundary conditions, the modified napkin ring specimen can be considered to be a suitable tool for assessing the static and fatigue failure properties of the bonded and clamped interface. Several tests with different clamping pressures are reported in [1-4].

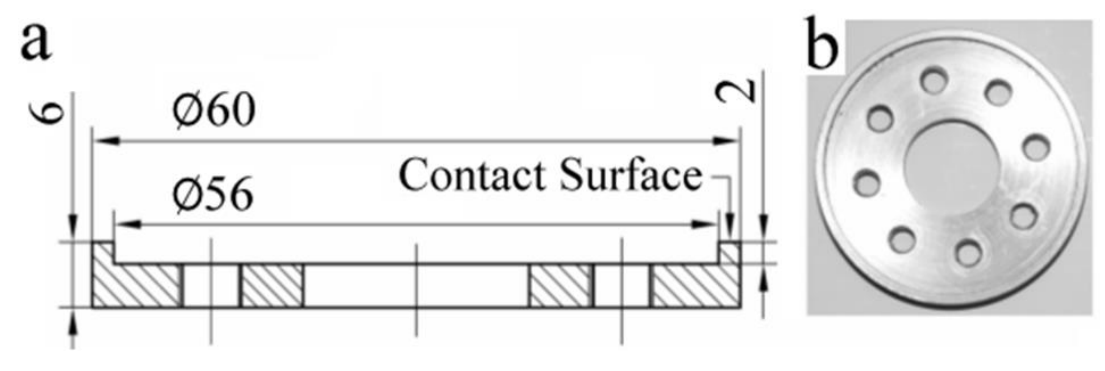

Figure 6. The modified napkin ring specimen and dimensions in [mm].

The quasi-static tests were performed by applying torsional displacement on one side of the specimen while the other side was rigidly supported. Relative displacement, $\Delta$, at the interface of the specimen pair was measured by an eddy current extensometer.

\subsubsection{Calibration of the cohesive model parameters}

The calibration of the parameters was carried out with a simple model of two blocks, as shown in Figure 7, using the finite element software, Abaqus. 


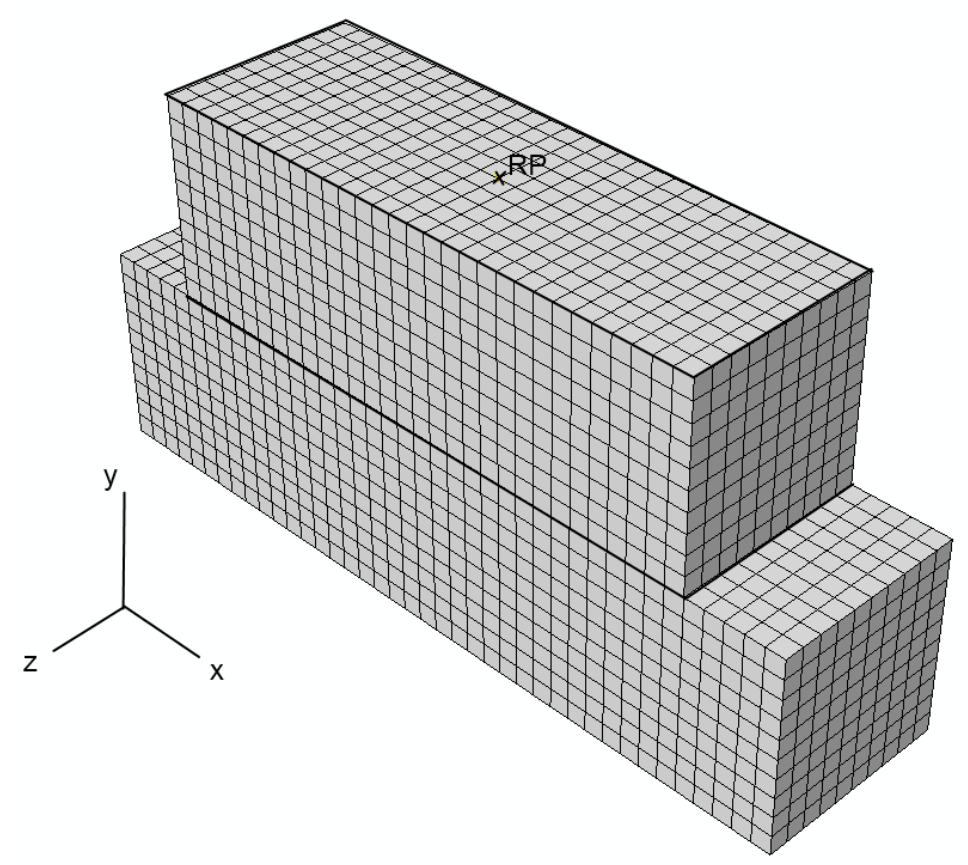

Figure 7. Finite element model to calibrate the parameters for the cohesive interface definition.

Both blocks measured $2 \mathrm{~mm}$ in width and the top and bottom blocks measured $6 \mathrm{~mm}$ and $8 \mathrm{~mm}$ in length, respectively. The blocks were given the material properties of steel ( $E=210 \mathrm{GPa}, \mathrm{v}=0.3$ ) and the surface-based cohesive behaviour and tangential penalty friction were defined as contact properties of the interface between the blocks. The loading was applied through boundary conditions to the reference point (RP) on the top surface. All of the nodes on the top surface were constrained to the reference point through the coupling constraint, in order to ensure that all displacements on the top surface were the same. All translations were restrained on the bottom surface. First of all, the normal clamping stress was applied by imposing a displacement in the negative $y$-direction on the reference point. The displacement was selected so that the average normal stress at the contact interface was either $50 \mathrm{MPa}$ or $100 \mathrm{MPa}$. Next, a velocity boundary condition in the local 1-direction was applied to the reference point while maintaining the compressive displacement. The upper block was allowed to slide by approximately $1 \mathrm{~mm}$.

According to Equation (7), the resulting peak traction of the clamped cohesive model is a sum of cohesive and frictional tractions, as is the traction during damage evolution. Therefore, the critical traction and damage evolution of the pure cohesion cannot be directly deduced from the napkin ring experimental data. Instead, the cohesive parameters have to be determined through trial and error until the modelled response corresponds to the experimental response.

The values for the stiffness, the coefficient of friction and the damage exponent were chosen based on earlier investigations [4]. As explained in more detail in [4], the damage is expected to be complete at $\delta_{m}{ }^{f}=1 \mathrm{~mm}$. The value of the critical traction was calibrated for the surface-based cohesive contact model. The values of the contact parameters to be used for the DL simulation are shown in Table 1. The shear properties are assumed to be equal in both directions, i.e. $K_{s s}=K_{t t}$ and $t_{s}^{0}=t_{t}^{0}$. In the absence of experimental data in the normal direction, the same stiffness and damage evolution properties are assumed as in the shear directions. The peak shear stress in the normal direction, $t_{n}^{0}$, is also unknown. For the sake of prudence, it is assumed that interfaces under tensile normal stress 
do not contribute to fatigue strength. The $t_{n}^{0}$ is assumed to be very small, which results in early damage in the contact points under positive normal stress. As a result, shear stresses are obtained only at the interface areas under compressive normal stress. This approach is expected to yield somewhat conservative results.

Table 1. Properties for the surface-based cohesive interaction.

\begin{tabular}{|c|c|}
\hline Interface property & Value \\
\hline$K_{n n}$ & $3000 \mathrm{~N} / \mathrm{mm}$ \\
\hline$K_{s s}=K_{t t}$ & $3000 \mathrm{~N} / \mathrm{mm}$ \\
\hline$\mu$ & 0.44 \\
\hline$\alpha$ & 5.33 \\
\hline$\delta_{m}^{f}$ & $1 \mathrm{~mm}$ \\
\hline$t_{n}^{0}$ & $1 \mathrm{MPa}$ \\
\hline$t_{s}^{0}=t_{t}^{0}$ & $55 \mathrm{MPa}$ \\
\hline
\end{tabular}

The simulated and experimental failure responses for the interfaces with clamping stresses $q=50 \mathrm{MPa}$ and $q=100 \mathrm{MPa}$ are shown in Figure 8.

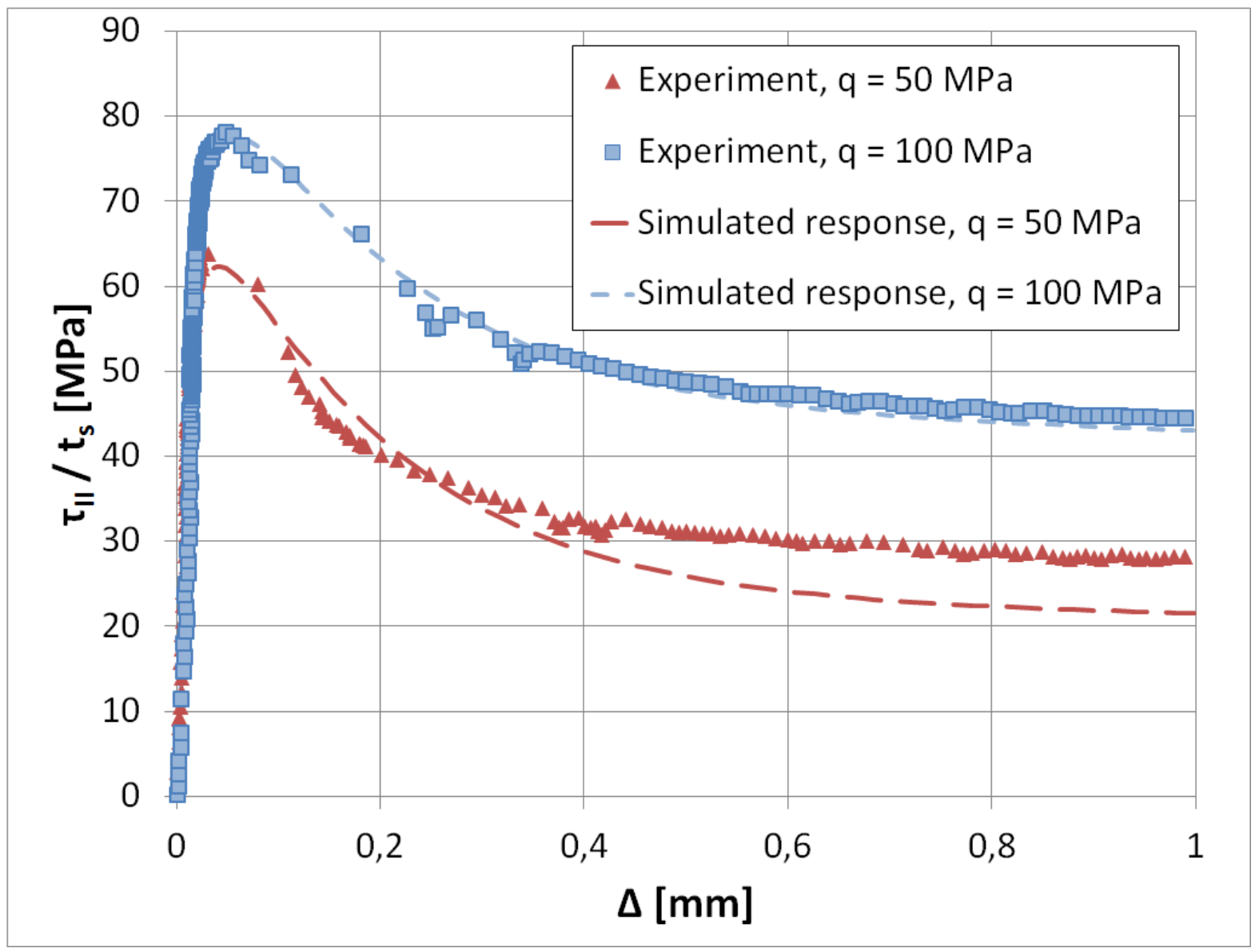


Figure 8. Experimental and simulated failure responses of the clamped and bonded interfaces under $q=50 \mathrm{MPa}$ and $q=100 \mathrm{MPa}$ clamping stress.

The coefficient of friction was chosen based on the behaviour of the specimens under $q=100 \mathrm{MPa}$ clamping stress.

\subsection{Modelling issues}

Contact modelling in Abaqus/Standard often leads to convergence issues which are overcome by damping assignments. Consequently, viscous regularization damping was used in this work. The effect of the regularization on the solution accuracy was estimated by conducting the same simulation with three different values of the viscosity coefficient, then comparing the results. It was observed that increasing the coefficient from 0.0001 to 0.0002 and 0.001 produced virtually identical results, while the calculation time was reduced to half and to one quarter, respectively. Thus, the viscous coefficient of 0.001 was used in subsequent simulations.

The simulation was performed with different mesh sizes so as to ensure that the error related to mesh size is minimal. The shear stresses changed by approximately $2 \%$ upon increasing the mesh size from $1 \mathrm{~mm}$ to $1.5 \mathrm{~mm}$. Refinement of the mesh beyond $1 \mathrm{~mm}$ resulted in convergence problems and very lengthy calculation times. Thus, the mesh size of $1 \mathrm{~mm}$ was chosen for the simulations.

Shear stress results are affected by the values of the contact interaction parameters. Therefore, the model was run three additional times and for each separate run, a different parameter (cohesive stiffness $K_{n n}, K_{s s}, K_{t t}$, damage evolution coefficient, $\alpha$, or coefficient of friction, $\mu$ ) was increased to three times the initial value. It was found that the increase in the cohesive stiffness had a significant effect on the resulting shear stress values, while the other parameters had less impact. Increasing the stiffness and the damage evolution coefficient made the convergence more difficult as damage behaviour became less smooth.

\section{Results and discussion}

\subsection{Quasi-static tests on the double lap joint}

Quasi-static tests were performed on the bonded/bolted and plain bolted double lap joint specimens. The load - displacement curves are shown in Figure 9. The maximum load for the bonded/bolted joint was $163 \mathrm{kN}$ and $31 \mathrm{kN}$ for the plain bolted joint.

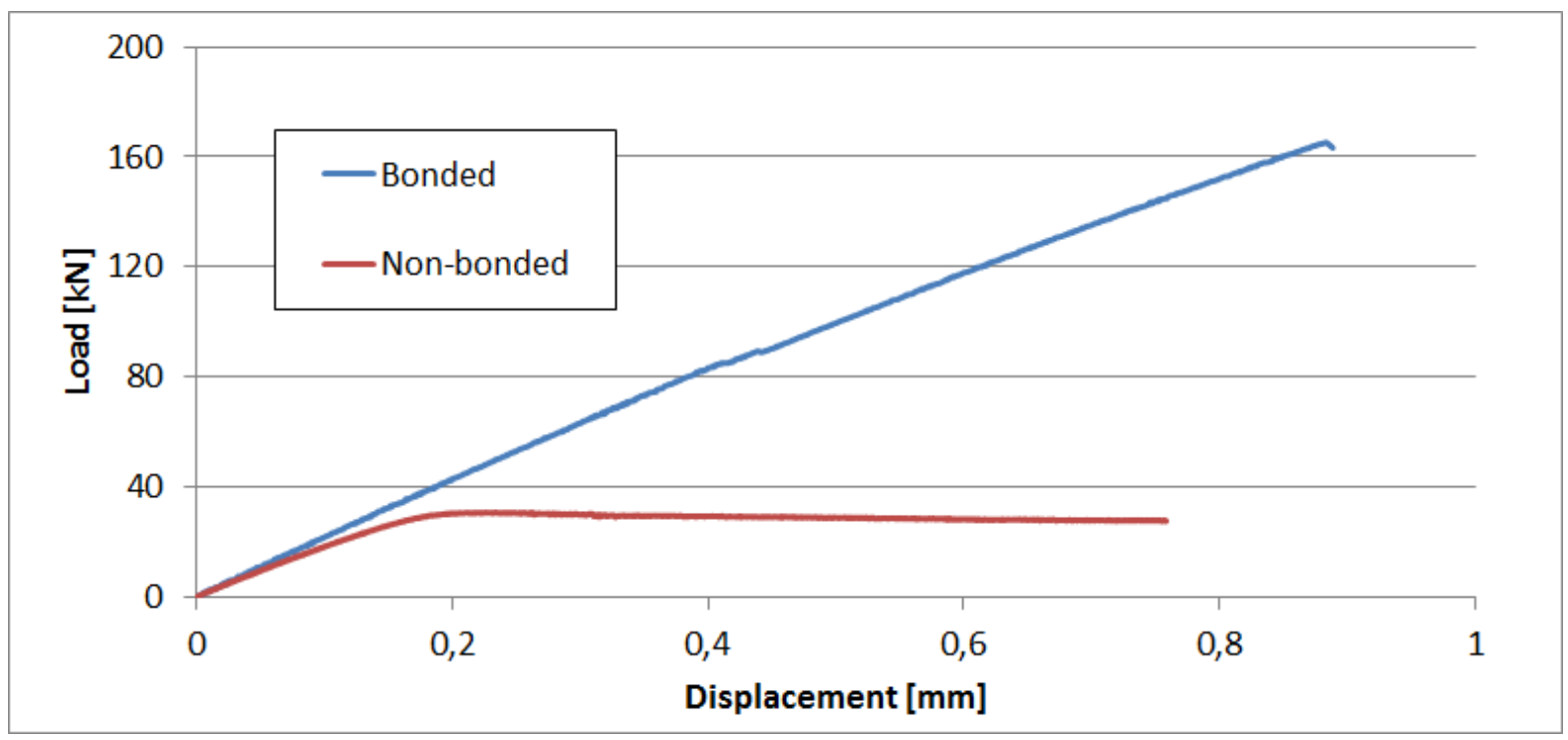


Figure 9. Quasi static response of the bonded and non-bonded double lap joints.

As can be seen in Fig. 9, both joints behave linearly at first. This is due to elastic elongation of the steel specimen. After the critical loading has been reached, the bonded/bolted joint fails abruptly. There is so much elastic energy stored in the specimen that sliding is not observed. The load is carried by friction in the plain bolted joint. Once the loading exceeds the frictional strength, steady frictional sliding begins.

\subsection{Fatigue tests and fatigue strength assessment}

The quasi-static strength of the plain bolted specimen was $31 \mathrm{kN}$, significantly lower than the strength of the bonded/bolted joint. Based on the fatigue tests on the non-bonded napkin ring specimen [1], which showed that the fatigue strength of the frictional interface is close to the quasi-static strength, the fatigue strength of the plain bolted specimen should also be in the same range as the static strength. This was implied by one run-out fatigue test at a load amplitude of $F_{\mathrm{a}}=25 \mathrm{kN}$. However, the strength of the plain bolted joint was so low, in comparison to the bonded/bolted joint, that it was decided to focus on the latter joints only.

All subsequent fatigue tests were conducted on bonded/bolted specimens. The small sample staircase methodology [5-7] was used for obtaining an estimate of the fatigue strength of the DLJ at $2 \times 10^{6}$ cycles. The range of experiments using the staircase series is shown in Table 2.

Table 2. Double lap joint fatigue tests.

\begin{tabular}{|cccc|}
\hline Specimen ID & $\begin{array}{c}\text { Load } \\
\text { amplitude, } \mathrm{F}_{\mathrm{a}}, \\
{[\mathrm{kN}]}\end{array}$ & $\begin{array}{c}\text { Failure }(\mathrm{X}) / \\
\text { Run-out }(\mathrm{O})\end{array}$ & $\begin{array}{c}\text { Number of } \\
\text { cycles to } \\
\text { failure, } N_{f}\end{array}$ \\
\hline $\begin{array}{c}\text { NB 1 (non- } \\
\text { bonded) }\end{array}$ & 25 & $\mathrm{O}$ & $>2 \times 10^{6}$ \\
\hline $\begin{array}{c}\text { Staircase series } \\
\text { B 1 }\end{array}$ & 75 & $\mathrm{O}$ & $>2 \times 10^{6}$ \\
B 2 & 80 & $\mathrm{O}$ & $>2 \times 10^{6}$ \\
B 3 & 85 & $\mathrm{X}$ & 554440 \\
B 4 & 80 & $\mathrm{X}$ & 808813 \\
B 5 & 75 & $\mathrm{X}$ & 955340 \\
B 6 & 70 & $\mathrm{O}$ & $>2 \times 10^{6}$ \\
\hline Additional fatigue tests & & & \\
B 7 & 90 & $\mathrm{X}$ & 26643 \\
B 8 & 90 & $\mathrm{X}$ & 47361 \\
B 9 & 95 & $\mathrm{X}$ & 34817 \\
\hline
\end{tabular}

In addition to the staircase series, three fatigue tests with higher load amplitudes were performed. These tests are also shown in Table 2.

From the results in Table 2, the sequence for the staircase analysis becomes OXXXO with $80 \mathrm{kN}$ as the starting load level $F_{a, 0}$. The loading interval is $d=5 \mathrm{kN}$ and the parameter $k=-0.48$ is read from [7]. Thus, the estimate for the fatigue strength of the bonded/bolted specimens becomes $F_{a, f}=77.6 \mathrm{kN}$.

It is interesting to compare the fatigue strength of the bonded and bolted joint to the fatigue strength of a welded joint with a similar structural geometry. According to the IIW recommendations, the fatigue strength of a structural detail can be assessed by using tabulated data of the fatigue resistance class (FAT class) [27]. Data from extensive experimental investigations have been produced into nominal stress based stress-life (S-N) curves. The $\mathrm{S}-\mathrm{N}$ curves are identified by the characteristic fatigue 
strength of the structural detail at $2 \times 10^{6}$ cycles and $95 \%$ probability of survival, the FAT class. The FAT class of the transverse loaded fillet weld lap joint is $63 \mathrm{MPa}$ if the failure occurs in the parent metal at the weld toe [27]. A simple estimate of the mean fatigue strength can be obtained by multiplying the FAT class by 1.5. Because the test specimens are relatively small and because the fatigue testing for completely reversed loading $(R=-1)$ is of interest, an additional stress ratio enhancement factor of 1.6 can be assumed [27]. Thus, without any post-weld improvement, the mean fatigue strength of the welded lap joint based on the nominal stress range in the main plate would be estimated as 151.2 $\mathrm{MPa}(=63 \mathrm{MPa} * 1.5 * 1.6)$. This corresponds to a load amplitude of $43.5 \mathrm{kN}$ for the dimensions of the current specimen. Thus, the hybrid joining technology clearly provides potential for fatigue strength improvement as compared to welded joints.

\subsection{Fatigue failure inspection}

All fatigue test results can be plotted to a load vs. number of cycles chart, as shown in Fig 10.

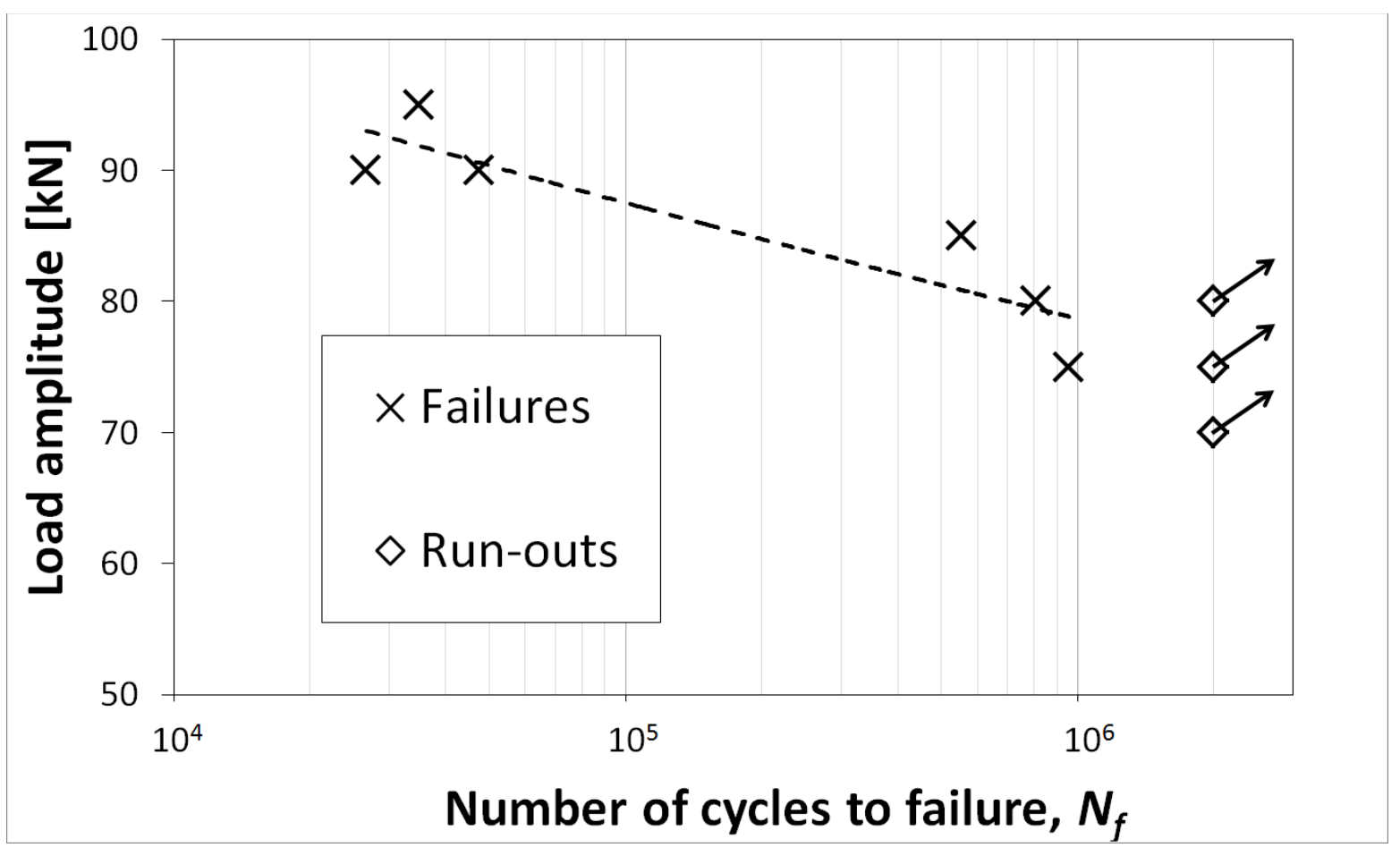

Figure 10. Load vs. fatigue life results of the DL specimens.

The data are limited, but some conclusions can be drawn from the fatigue failures. The specimens loaded with amplitudes of $F_{a}=90$ and $95 \mathrm{kN}$ had much shorter fatigue lives than the specimens loaded with lower amplitudes. The difference is probably due to the failure type which was found to be different depending on the load and the life. The specimens with long life had severe fretting damage in the contact interfaces, while the specimens with short life were less damaged. With high loads, failure is perhaps dominated by the progressive damage of the adhesive, so there is not enough time for fretting damage to occur before adhesive damage becomes critical and final failure occurs. Figure 11 shows the fractured interfaces of specimens B 4 (long life) and B 8 (short life) after fatigue loading and disassembly. Severe fretting damage can be seen in specimen B 4 around both the small and large bolt holes on the loading side. Similar but milder damage can be seen around the small hole in specimen B 8. The damage is located approximately at the edge of compressive contact. The damage around the large bolt hole in specimen B 8 is different. In this case most of the damage is located in the area under compression. All specimens that failed at a relatively low number of cycles $\left(N_{f}<10^{5}\right.$ cycles) sustained this type of damage around at least one of the bolt holes. 

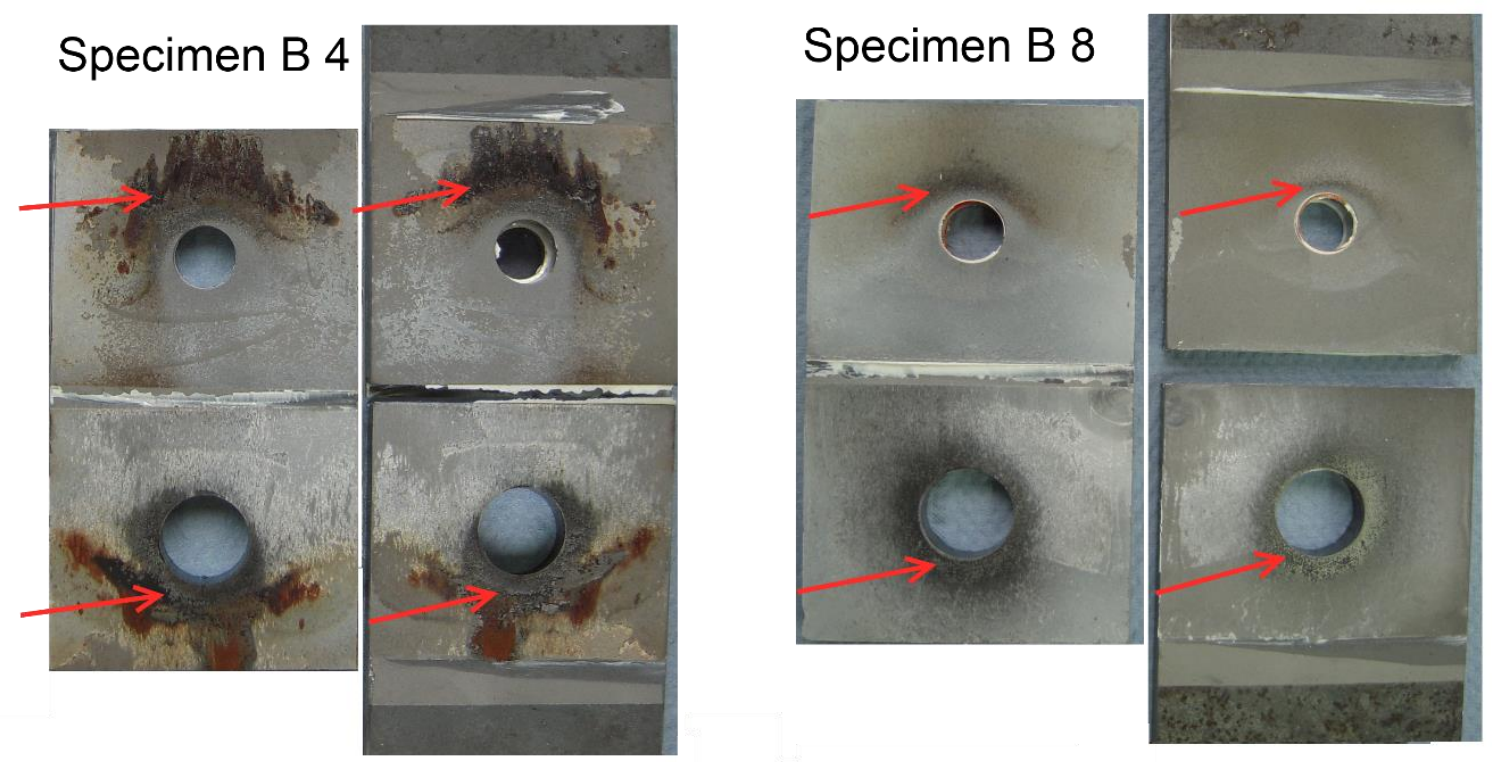

Figure 11. Specimens B 4 and B 8 after fatigue loading and disassembly.

Although fretting damage was found in most of the cyclically-loaded specimens, the final failure was probably caused by shear decohesion. This is because no cracks were found in the steel specimens. However, when contemplating the design of hybrid bonded/bolted joints, the risk of fretting fatigue should be considered. Figure 12 shows the interface in one specimen with the fretting debris removed. There is a notch which was formed due to fretting and it is possible that a crack would have propagated from the notch. It is worthwhile to point out that the addition of adhesive into the bolted joint dramatically changes the fatigue behaviour of the joint. The same DU specimen without adhesive would be in the gross slip state at axial loads much lower than the ones applied here. Since the bonded and clamped interface can withstand higher stress than the plain frictional interface, the bulk stresses in the bonded/bolted joints can be higher than in plain bolted joints and the risk of fretting fatigue crack growth should be assessed. 


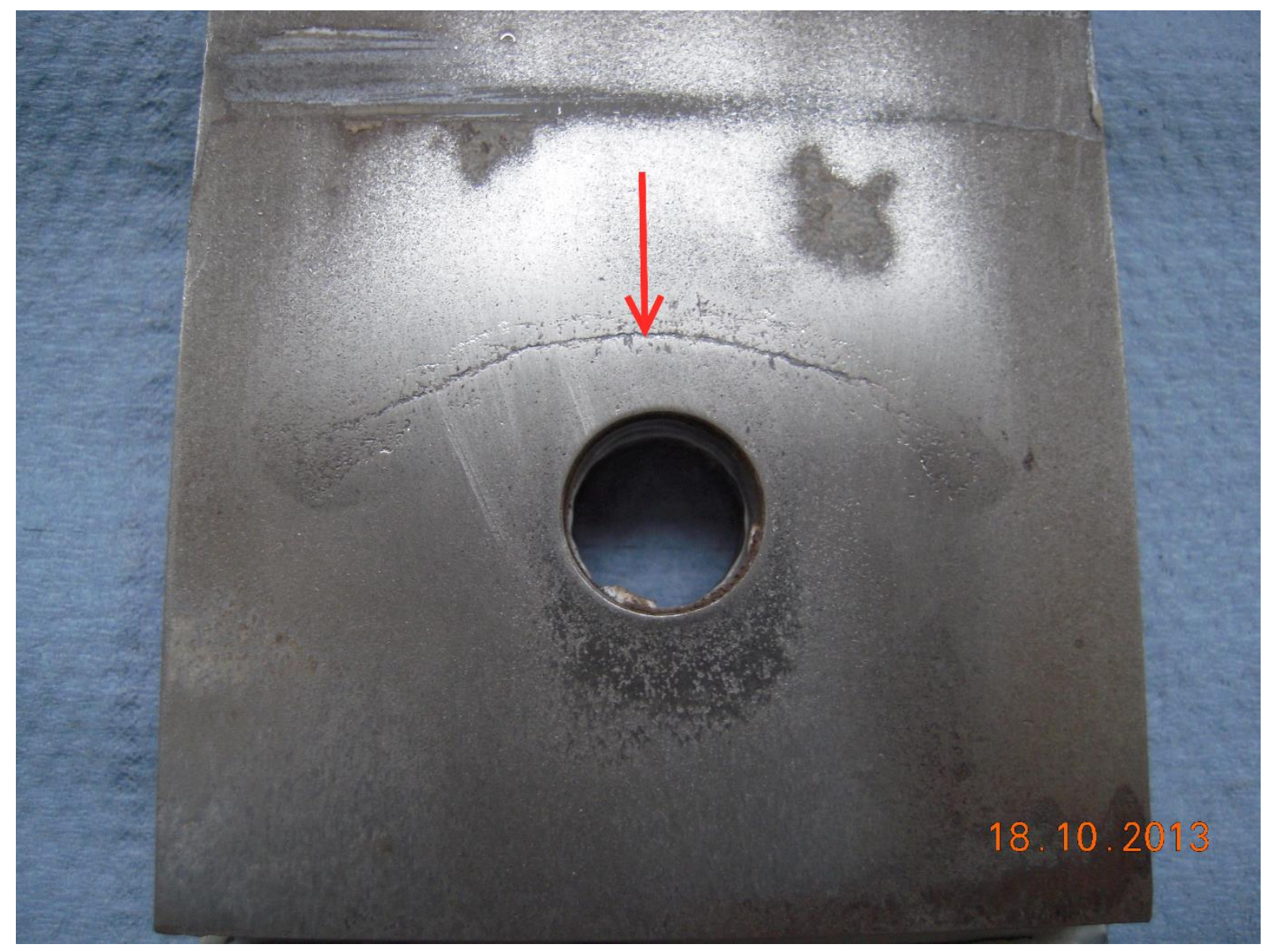

Figure 12. Fracture interface after removing fretting debris.

The displacement response of the DL specimens during fatigue loading was measured by the built-in displacement sensor of the fatigue test machine and, for most specimens, a clip-on gage was attached to one side of the gap between the two main plates. Typically, the specimen response was linearelastic at the beginning of the fatigue life. Towards the end of the fatigue life, slipping hysteresis was measured by the clip-on gage. The measured slip amplitude vs. the number of cycles for specimen $B$ 4 (see Table 2 ) is shown in Figure 13. The load-displacement $\left(F-\Delta_{\text {gap }}\right)$ loops measured by the clip-on gage are shown at $5 \times 10^{5}, 7 \times 10^{5}$ and $8 \times 10^{5}$ cycles. 


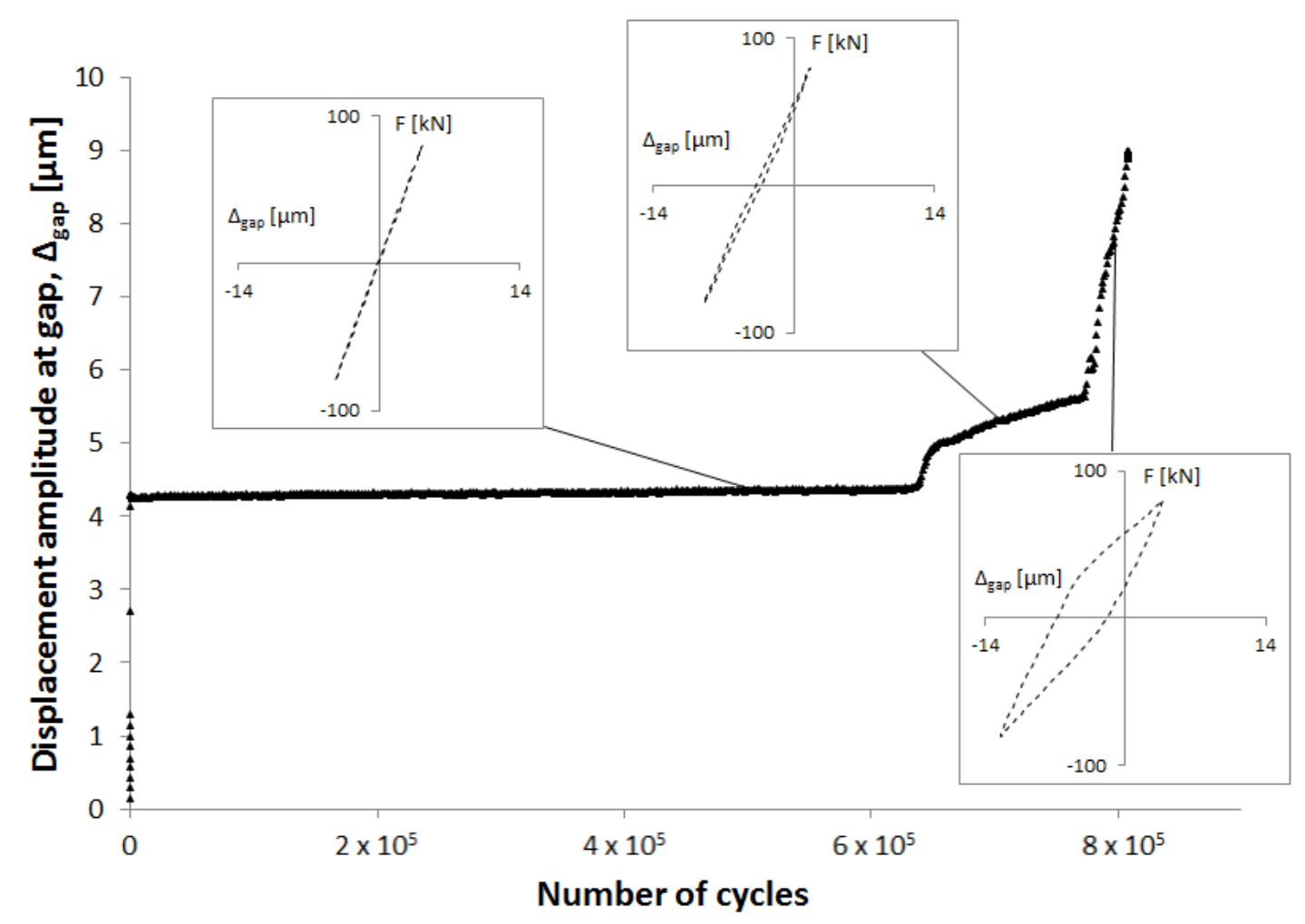

Figure 13. Displacement amplitude measured at the gap between the main plates vs. the number of cycles on specimen B 4. The load - displacement hysteresis is shown at $5 \times 10^{5}, 7 \times 10^{5}$ and $8 \times 10^{5}$ cycles.

The shape of the displacement amplitude curve in Fig. 13 is typical for all specimens that failed in fatigue. At first there is a region of very slow but steady increase in the slippage characterized by linear-elastic load-displacement response. After a relatively large number of cycles a sharp increase in slippage occurs, and slipping hysteresis is measured during the subsequent loading cycles. The increase in slippage tends to level down, however, final failure occurs after a relatively small number of cycles. In the first region, the load is probably carried almost exclusively by the adhesive with slow progressive damage occurring due to the cyclic loading. The sharp increase in slippage occurs after the damage in the adhesive has reached a critical amount, and the slipping hysteresis observed after this is due to frictional sliding. The specimen contains four interfaces where the damage is in effect not identical. Thus, it is possible that one of the bonded interfaces failed before the others, thereby resulting in the first increase in slippage. The interface on the other side of the specimen would have then started to carry most of the load, resulting in relatively fast fatigue failure.

Based on the damage in the specimens shown in Figure 11, it is clear that sliding also occurred in the interfaces under the large bolt, whereas it had been originally planned that slipping would only occur in the interfaces under the small bolt. This is the case in static fracture, where the whole interface fails virtually at once. The specimen was modified for a few additional fatigue tests to study the fatigue failure. Two spherical thrust bearings were used instead of regular washers under the large bolt, in order to distribute the clamping stress to a wider area which encompassed almost the entire interface area. The diameter of the bearing was $55 \mathrm{~mm}$ and its thickness, $20 \mathrm{~mm}$. At the same time, the effect of bolt pre-load was studied. For the first test, the small bolt had the same pre-load $(43 \mathrm{kN})$ as applied in all previous fatigue tests. The other two tests were conducted with different pre-loads on the small 
bolt, specifically, $10 \mathrm{kN}$ and $55 \mathrm{kN}$. The loading amplitude was chosen so that a similar type of failure would be obtained. The modified fatigue tests are summarized in Table 3.

Table 3. Modified double lap joint fatigue tests.

\begin{tabular}{|cccc|}
\hline Specimen ID & $\begin{array}{c}\text { Load } \\
\text { amplitude, }[\mathrm{kN}]\end{array}$ & Bolt preload & $\begin{array}{c}\text { Number of } \\
\text { cycles to } \\
\text { failure, } N_{f}\end{array}$ \\
\hline M 1 & 90 & $43 \mathrm{kN}$ & 277730 \\
M 2 & 75 & $10 \mathrm{kN}$ & 96532 \\
M 3 & 90 & $55 \mathrm{kN}$ & 153323 \\
\hline
\end{tabular}

The specimen M 1 had significantly higher fatigue life than specimens with the initial configuration that were loaded with the same amplitude (see Table 2). Ideally, all of the specimens would fail in the same location. However, the factors affecting the total strength of the joint, such as surface roughness and adhesive material properties, have a statistical nature. As a result, the more there are possible failure locations, i.e. locations with high stress concentration, the higher the probability of early failure. With the modified specimens, the number of locations with high stress concentrations was reduced and, therefore, it is logical that a longer fatigue life was measured. Fretting fatigue with a notch similar to Figure 12 was observed around the small bolts in the modified tests $M 1$ and M 3, while the plates under the bearing washer and large bolt had no such signs of stress concentrations. Nevertheless, the areas under the large bolt were damaged due to fretting, and some of them failed during the tests.

The modified specimen M 2, which had the lowest bolt pre-stress, failed differently, as compared to the other specimens, specifically, there was no fretting damage. The strength was lower than for specimens $\mathrm{M} 1$ and $\mathrm{M} 3$, which indicates that the clamping stress improved the joint fatigue strength. The same has been observed for plain bolted joints [11-13], however, with higher clamping stress, the risk of fretting fatigue is increased. As a result, the bolt pre-stress has been found to increase the fatigue strength up to a point, but after fretting fatigue occurs, further increase in pre-stress does not improve the fatigue strength. Indeed, based on the limited results here (specimens $M 1$ and $M 3$ ), the increase in clamping stress does not seem to increase fatigue strength of the bonded/bolted joint after the occurrence of fretting.

Even though the thrust bearing distributed the load to a wide area, the specimen still showed some fretting damage at the interface under the large bolt, although the stress concentration acting as a possible initiation location for fretting cracks was avoided. In real joints, it is very difficult to apply uniform clamping to the entire bonded area. Therefore, the edge of compressive contact should be considered as the critical location for fatigue damage. Furthermore, the question can be raised whether or not the use of large bolts and high clamping stress improves fatigue resistance.

\subsection{Finite element analysis}

The fracture of the joint is governed by interface shear strength. Therefore, the traction stresses at the cohesive interface were read from the surface output variables CPRESS and CSHEAR, which provided the contact pressure and contact shear traction components, respectively. The contact shear stress $\tau_{1}$ along the local 1-direction at remote loading $P=P_{\max }$ and $P=P_{\min }$ in step 2 can be seen in Figures 14 a and c, respectively and the contact pressure, $\sigma_{2}$, at $P=P_{\max }$ and $P=P_{\min }$ can be seen in Figures $14 \mathrm{~b}$ and $\mathrm{d}$, respectively. Only the contact surface is plotted. 

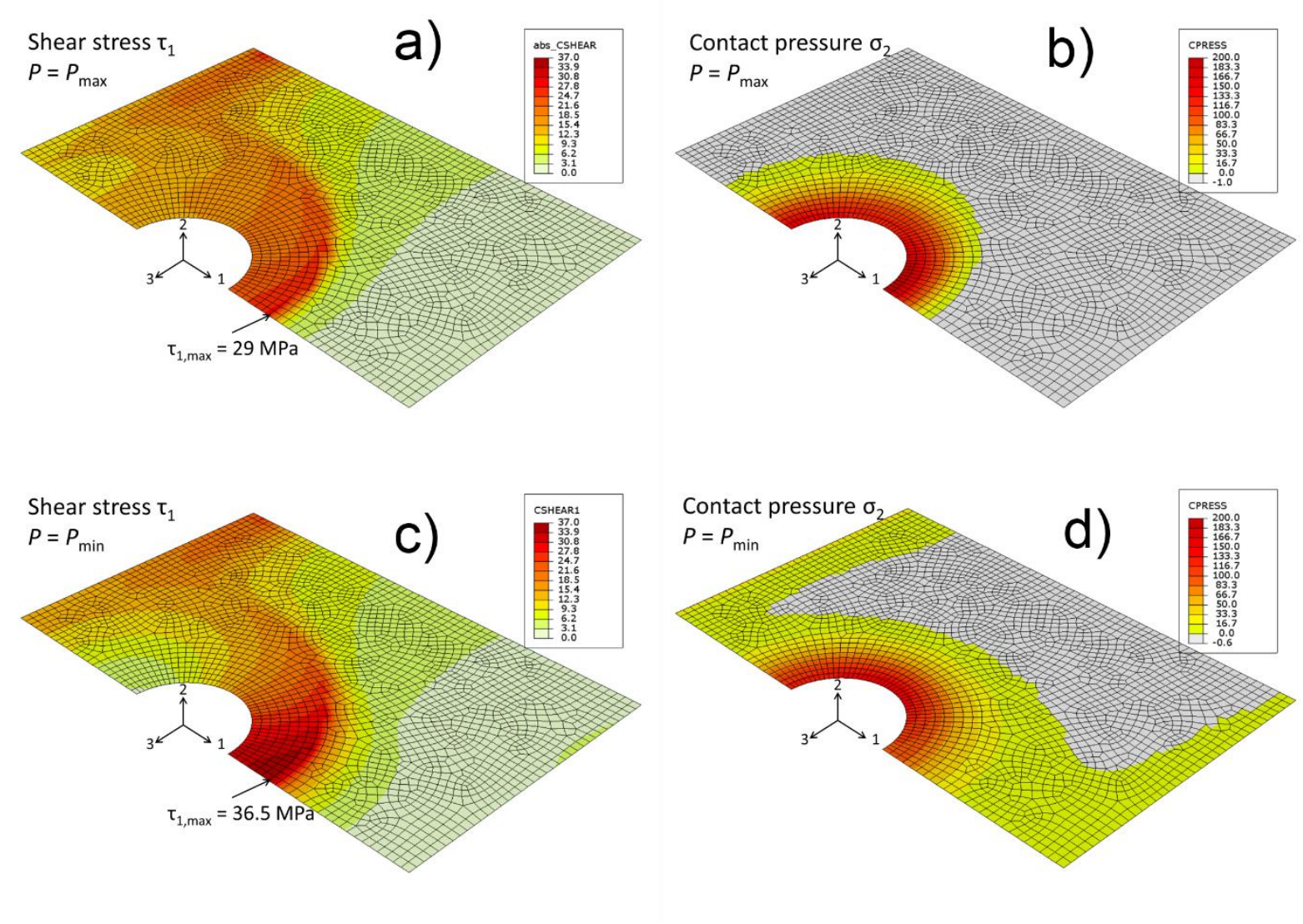

Figure 14. The interface stress distribution. a) Shear stress in the 1-direction at $\left.P=P_{\max }, \mathrm{b}\right)$ contact pressure at $P=P_{\max }, \mathrm{c}$ ) Shear stress in the 1-direction at $P=P_{\min }$ and d) contact pressure at $P=P_{\min }$. Locations and values of the maximum shear stresses are indicated.

The highest value of the shear stress component in the longitudinal direction is $\tau_{1}=29.5 \mathrm{MPa}$ at $P=$ $P_{\max }$ and $\tau_{1}=36.5 \mathrm{MPa}$ at $P=P_{\min }$. In the transversal direction the shear stresses were much lower and thus, the failure was governed by the shear stress in the direction of the applied remote load. The maximum tractions occurred in the locations shown by the arrows in Figs. 14 a and c. The maximum shear stress occurred at a distance of approximately $6 \mathrm{~mm}$ from the edge of the bolt hole, next to the centre line.

In our previous study, the shear fatigue strength of the bonded and clamped interface under $q=50$ $\mathrm{MPa}$ clamping was found to be $\tau_{f}=19 \mathrm{MPa}$, and under $q=4 \mathrm{MPa}$, the fatigue strength was $\tau_{f}=21$ $\mathrm{MPa}$ [1]. At $P=P_{\max }$, the contact pressure at the location of maximum shear stress is $\sigma_{2}=9 \mathrm{MPa}$. At $P=P_{\text {min }}$, the contact pressure is $\sigma_{2}=55 \mathrm{MPa}$. Thus, the shear stress exceeds the interface fatigue strength during tensile and compressive loading and it is concluded that the joint is likely to fail before $2 \times 10^{6}$ cycles with the applied loading. The model can be used to find a remote loading that creates shear stresses that do not exceed the fatigue strength. The maximum traction of $\tau_{1}=19 \mathrm{MPa}$ is found to occur with the remote loading of $P=107 \mathrm{MPa}$. This corresponds to the loading amplitude of $F_{a}=$ $61.6 \mathrm{kN}$ during the experiment. The fatigue strength of the DL was found experimentally to be $F_{a, f}=$ $77.6 \mathrm{kN}$. Thus, the simulation provides conservative results, as expected. It should be recalled that the critical traction in the positive normal direction was set to $t_{n}^{0}=1 \mathrm{MPa}$, since the contribution of positive 
normal tractions to fatigue strength was assumed to be negligible. This assumption was clearly conservative. However, in the absence of better understanding, it is a safe assumption. The positive normal stress in the DU is caused by shear lag, i.e. the top plates tend to bend as the main plate is pulled. The highly-exaggerated deformations of the DL are shown in Figure 15. The area under positive normal stress is damaged during the loading up to $P_{\max }$ because of the assumption $t_{n}^{0}=1 \mathrm{MPa}$.

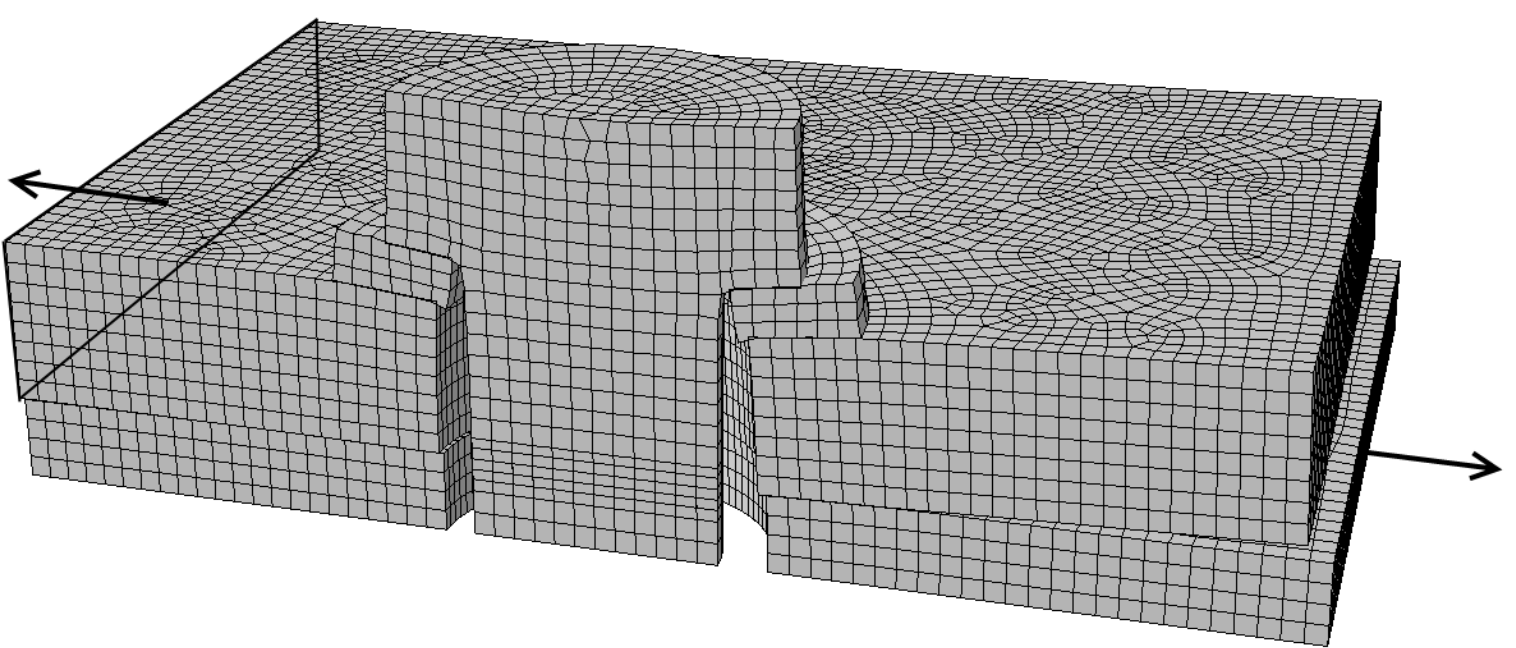

Figure 15. Exaggerated deformations of the DL model showing the shear lag effect.

The amount of interface damage at $P=P_{\max }$ can be seen in Figure 16. 


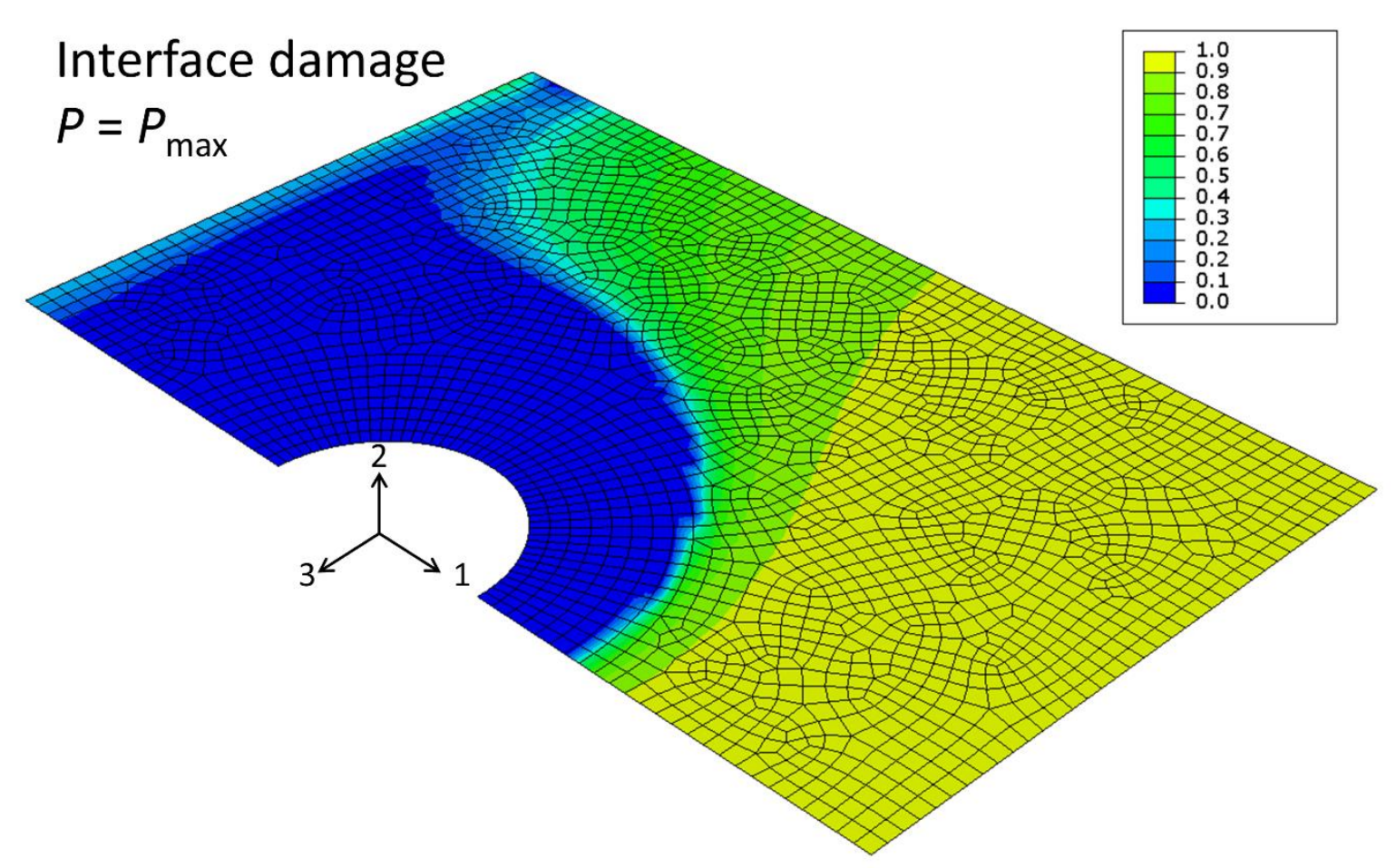

Figure 16. Damage at $P=P_{\max }$. Yellow indicates almost total damage and blue indicates almost zero damage.

Damage is nearly total in the yellow-coloured areas in Fig. 16, while the blue-coloured area is not damaged at all. The direct result of the assumption that critical normal traction is small is that load is mostly carried by the area under compressive normal stress around the bolt hole and the area near the middle of the specimen where normal stress is low. When comparing Figures 11,12 and 16, it can be seen that the area with fretting damage starts approximately at the edge of the damaged area, according to the simulation. Figure 14 shows that the maximum traction occurs at the edge of the area under compression. This is the edge of sticking contact, where the contact status changes between slipping and sticking during cyclic loading and, consequently, where fretting fatigue cracks are initiated. However, the clamping stress at the location of maximum traction is only 9 to $55 \mathrm{MPa}$, which should result in shear decohesion failure according to [1]. Under low clamping stress, fretting does not necessarily lead to crack initiation but can cause damage to the interface, as was observed in the DL specimens.

The analysis presented in this paper shows the critical locations in the interface where fatigue failure is concerned. It can also be used to estimate whether or not the interface will fail before $2 \times 10^{6}$ cycles under fatigue loading. However, no estimation of fatigue life can be carried out. A more detailed analysis of the interface fatigue failure would require a progressive fatigue damage model of the adhesive combined with fretting fatigue analysis.

\section{Conclusions}

The fatigue response of the bonded and bolted double lap joint was studied experimentally and by using finite element analysis. The fatigue strength of the double lap joint at $2 \times 10^{6}$ cycles was measured experimentally under fully reversed loading by using the small sample staircase scheme. Additional fatigue tests were performed at higher load amplitudes and also using a modified geometry with a better-controlled location of failure. The fatigue strength was also estimated through interface shear 
and normal stresses calculated using FEM and compared with the fatigue strength of clamped and bonded interfaces previously determined by using napkin ring specimens. The following conclusions can be drawn.

- The experimentally measured fatigue strength of the bonded/bolted double lap joint was found to be higher than the fatigue strength of a welded joint with a similar structural geometry (according to IIW design recommendations [27]). Therefore, the hybrid joining technology clearly provides potential for fatigue strength improvement.

- It was suggested that the fatigue failure results from the simultaneous progressive damage in the adhesive and the fretting damage initiated from the edge of compressive contact. However, no fretting cracks were found in the specimens which leads to the conclusion that shear decohesion was the ultimate cause of failure.

- No fretting damage was observed in specimens with relatively low fatigue life (high loading). Thus, the failure is assumed to occur mainly due to shear decohesion.

- The fatigue strength seems to increase with bolt pre-load until fretting damage starts to dominate. However, the number of fatigue tests is too small to confirm the effect of bolt preload.

- A preliminary estimate of the failure / non-failure response of the DLJ can be realized by comparing the normal stress / shear stress conditions, as solved using the finite element method, to the shear fatigue strength values of the bonded and clamped interface reported in [1].

- The damaged area and the location of maximum shear stress according to the finite element solution correspond well to the area with the most fretting damage in the specimens.

\section{Acknowledgements}

This work was supported by the Finnish Graduate School in Engineering Mechanics. Partial support was also provided by Ruukki and the Finnish Metals and Engineering Competence Cluster (FIMECC). CSC-IT Center for Science Ltd. is acknowledged for the allocation of computational resources.

\section{References}

[1] Hurme S, Marquis $G$ (2013) The effect of clamping stress on the fatigue strength of bonded highstrength steel interfaces. Weld World 57:285-292

[2] Oinonen A, Marquis G (2011) A parametric shear damage evolution model for combined clamped and adhesively bonded interfaces. Eng Fract Mech 78:163-174

[3] Hurme S, Oinonen A, Marquis G (2011) Fatigue of bonded steel interfaces under cyclic shear loading and static normal stress. Eng Fract Mech 78:1644-1656

[4] Oinonen A, Marquis G (2011) Shear decohesion of clamped abraded steel interfaces reinforced with epoxy adhesive. Int J Adhes Adhes 31:550-558

[5] Dixon W J, Mood A M (1948) A method for obtaining and analyzing sensitivity data. J Am Statist Assoc 43:109-126

[6] Dixon W J (1965) The up-and-down method for small samples. J Am Statist Assoc 60:967-978

[7] Little R E (1974) The up-and-down method for small samples with extreme value response distributions. J Am Statist Assoc 69:803-806

[8] Nowell D, Dini D, Hills D A (2006) Recent developments in the understanding of fretting fatigue. Eng Fract Mech 73:207-222 
[9] Ciavarella M, Demelio G (2001) A review of analytical aspects of fretting fatigue, with extension to damage parameters, and application to dovetail joints. Int J Solids Struct 38:1791-1811

[10] Nesládek M, Španiel M, Jurenka J, Růžička J, Kuželka J (2012) Fretting fatigue - Experimental and numerical approaches. Int J Fatigue 44:61-73

[11] Benhamena A, Talha A, Benseddiq N, Amrouche A, Mesmacque G, Benguediab M (2010) Effect of clamping force on fretting fatigue behaviour of bolted assemblies: Case of couple steelaluminium. Mater Sci Eng A 527:6413-6421

[12] Chakherlou T N, Razavi M J, Abazadeh B (2013) Finite element investigations of bolt clamping force and friction coefficient effect on the fatigue behaviour of aluminium alloy 2024-T3 in double shear lap joint. Eng Fail Anal 29:62-74

[13] Wagle S, Kato H (2009) Ultrasonic detection of fretting fatigue damage at bolt joints of aluminium alloy plates. Int J Fatigue 31:1378-85

[14] Volkersen, O (1938) The rivet load distribution in tensile loaded riveted joints with constant lap cross sections (Die Nietkraftverteilung in zugbeanspruchten Nietverbindungen mit konstanten Laschenquerschnitten). Luftfahrtforschung 15:41-47

[15] Kwakernaak A, Hofstede J, Poulis J, Benedictus R (2010) Improvements in bonding metals (steel, aluminium). In: Dillard D A, (Ed.), Advances in structural adhesive bonding. Woodhead Publishing Limited, Cambridge, pp. 185-236

[16] De Bruyne N A (1944) The strength of glued joints. Aircraft Engineering. 16:115-118

[17] Tsai M Y, Oplinger D W, Morton J (1998) Improved theoretical solutions for adhesive lap joints. Int J Solids Struct 35:1163-1185

[18] Osnes H, McGeorge D (2009) Experimental and analytical strength analysis of double lap joints for marine applications. Composites B 40:29-40

[19] Gonçalves J P M, De Moura M F S F, de Castro P M S T (2002) A three-dimensional finite element model for stress analysis of adhesive joints. Int J Adhes Adhes 22:357-365

[20] Griffith A A (1921) The phenomena of rupture and flow in solids. Philosophical transactions of the Royal Society. A221:163-198

[21] Castagnetti D, Dragoni E, Spaggiari A (2011) Failure analysis of complex bonded structures: Experimental tests and efficient finite element modeling by tied mesh method. Int J Adhes Adhes 31:338-346

[22] De Moura M F S F, Gonçalves J P M, Chousal J A G, Campilho R D S G (2008) Cohesive and continuum mixed-mode damage models applied to the simulation of the mechanical behavior of bonded joints. Int J Adhes Adhes 28:419-426

[23] Roe K L, Siegmund T (2003) An irreversible cohesive zone model for interface fatigue crack growth simulation, Eng Fract Mech 70:209-232

[24] Moroni F, Pirondi A (2011) A procedure for the simulation of fatigue crack growth in adhesively bonded joints based on the cohesive zone model and different mixed-mode propagation criteria, Eng Fract Mech 78:1808-1816 
[25] Khoramishad H, Crocombe A D, Katnam K B, Ashcroft I A (2010) Predicting fatigue damage in adhesively bonded joints using a cohesive zone model, Int J Fatigue 32:1146-1158

[26] Abaqus User Manual, version 6.12, 2012

[27] Hobbacher, A (2009). IIW Recommendations for Fatigue Design of Welded Joints and Components. WRC Bulletin 520, The Welding Research Council, New York 